\title{
Post-Graduation Internship between Exploitation and Training: A Research on the Italian Experience
}

\author{
By Davide Arcidiacono*
}

The research is an analysis about conditions and regulatory forms of internship, providing empirical evidence on the case of postgraduate internships carried out in Italy in the last two years, trying to assess the quality of the learning environment where the interns worked and the effectiveness of internship in guiding and promoting the employability of graduates. The study is based on the results collected through a sample of graduates between 2011 and 2012 (N = 1154) using the CAWI method. First, data highlight how interns are in a condition of "role ambiguity" in which there is a clear contrast about the clearness of information and conditions in which they operate and the expectations of bosses and colleagues about the tasks to be performed. Nevertheless, interns do not get adequate training input, they remain confined to limited aspects of their job and they do not got an overall knowledge of business activities, that in some way could limit their operational capacity and understanding of the "production" processes in the company. More problematic, however, is the impact of internship on employability. The weak capability of post graduate internship to promote employability has to be contextualized considering the peculiarities of the local labor market of a South-European country, mostly characterized by micro- entrepreneurship, family business, above all in the service sector with low added value and with a high tendency to use informal work.

\section{Introduction}

One of the objectives of European Strategy for employment of young people, particularly those highly skilled, has always been encouraging the school-work alternation (Muller and Gangl 2003, Walther 2006). Similarly, one of the priority objectives of the Bologna Process, and the growing debate about the employability of graduates, was getting closer education and firms, particularly in Mediterranean countries, which tertiary educational systems have been often accused of self-referentiality and misalignment to the needs of labor demand (Regini 2010). Therefore, internship, as a means of alternation, plays a double role: on one hand, it encourages the acquisition of technical

${ }^{*}$ Researcher, University of Catania, Italy. 
skills combining learning by absorbing with learning by doing or by interacting; from the other hand, it would contribute to the construction of a professional self, as a moment of recognition of the value and limitations of the skills possessed, helping to curb the phenomena of over-education and job mismatch between demand and supply of skilled labor forces. These functions, guidance and active learning, become even more essential at a time when career of educated people are becoming more complicated, fragmented and uncertain (Standing 2011). The reference model in Europe continues to be the German "dualistic system", very expensive and difficult to replicate in different contexts, but capable to establish cooperative relations and exchanges with the business system to train more specialized and suitable skills. However, the institutional framework of internship in Mediterranean country, like Italy, is really ambiguous because norms and actors don't define clearly if it is a training time or a work experience, respect to the French model, where it is strictly linked to a training path, or the anglo-saxon "open market" model, where internships are considered more clearly as an entry level job. Strengthening internship get in crisis the pedagogical "two times" model, typical of country like Italy, which clearly separates the moment of education from the moment of work. Now, internship become more and more a signal or an access credential (Spence 1973, Collins 1972, Hanson et al. 2013) to the labor market, also contributing to the building of those weak ties that are at the basis for success in job searching (Granovetter 1973, Mouw 2003).

European data confirm how the opportunities of employment show some correlation with internship (Peschner 2013), so much so that $61 \%$ of young Europeans would find a job after an internship (McKensey 2012), but this percentage get lower in the Italian case (only 46\%). However, the risks that internship is transformed in some way in a non-standard labor contract and a low cost strategy for the employment of young skilled labor forces, seems to be a central concerns of governments, such as in the recent reform of internships in France in 2006, after the protests of the movement Generation Precarie, or the recent Italian reform of 2012, that introduces through rules and tougher sanctions to limit possible abuses in the use of trainees in the company (Adapt 2013). This fact is especially relevant at the time of the launch of the Youth Guarantee Program in Europe, which seems to further highlight the importance of school-work transition to ensure a better employability of young people, especially those more educated.

\section{Objectives and Methodology}

The paper tries to respond to the following heuristic questions and purposes:

- assess the quality of the learning environment for trainees: what are the operating conditions and how the company supports the learning process of graduates? 
- Is Internship really effective in guiding and promoting the employability of graduates?

These cognitive objectives have been pursued through a survey to a stratified sample of graduates between 2011 and $2012(\mathrm{~N}=1157)$ at the University of Catania. The administration of the questionnaire was done using the Cawi Method. For the analysis of the relationship between training and employability, we proceeded to construct a binary regression model, accepting relations with a significance level of $\leq 0.05$.

The survey, although a local study, it may be useful to put in question the value of internship instrument considering at the same time the peculiarity of national model of regulation and currently considering the constraints that may emerge in a Southern reality, characterized by higher unemployment of educated people and with considerable disparities both in terms of efficiency and dynamism of the economic system (Reyneri and Pintaldi 2013, Avola and Cortese 2013). Moreover, the local dimension of the survey appears as an advantage for evaluating how the processes of coercive isomorphism and convergence at European level face with the attributes and the socioinstitutional environment of a certain territory.

\section{Internship in Italy: Conditions and Effects}

\section{The Learning Environment}

A first element to examine the real value of the internship is the learning environment in which the interns have to work.

The training program, the main document where the personalized learning path and the operating conditions of the internship are described in details, is a starting point for this analysis. The contents of the training program are for the most part $(45 \%)$ defined in a static perspective, considering above all contingencies linked to the business in a short term perspective, more simply considering only the job vacancies. Rarely the training program is the result of an annual planning activity performed on the basis of an efficient monitoring of corporate needs, nor is it based on the construction of innovative projects that look to interests and possible future investment company (only in $27 \%$ of cases) in areas where the inclusion of new skilled labor forces may play an important role also in the production of innovation. In addition, only in $20 \%$ of cases there was a co-construction and a real collaboration between firms and the promoter of the internship, like University, as expected and desirable considering the provision of the recent university reform and the recent national guidelines on internships.

Data show also a low level of corporate investment on training activities for trainees. The interns interviewed have no problem to say that in almost half the cases there was not any form of training when they start their experience inside the firm (Figure 1) and there have been entrusted for the most part by tutoring and direct practice on the job. Other forms of training appear less 
used in the analyzed sample, above all that are more geared to the acquisition of knowledge about the overall strategies and internal work processes, such as company visits (used in approximately $20 \%$ of cases) or job rotation experience (only $13 \%$ of trainees). If we also look at the content of this training, it is not surprising that almost all the trainees converge on technical skills related to the task and the reality of the host firm (firm-specific), and only a residual seems to concern skills (such as language skills or computer) expendable outside the company (less than $40 \%$ of the cases), or skills related to the overall management of the company that can help the trainee in a deeper understanding of business dynamics and processes (organizational culture and values, but also products, markets and strategies) which covers about only $30 \%$ of the interns interviewed.

Figure 1. How many Days were dedicated to Training Input (\%)

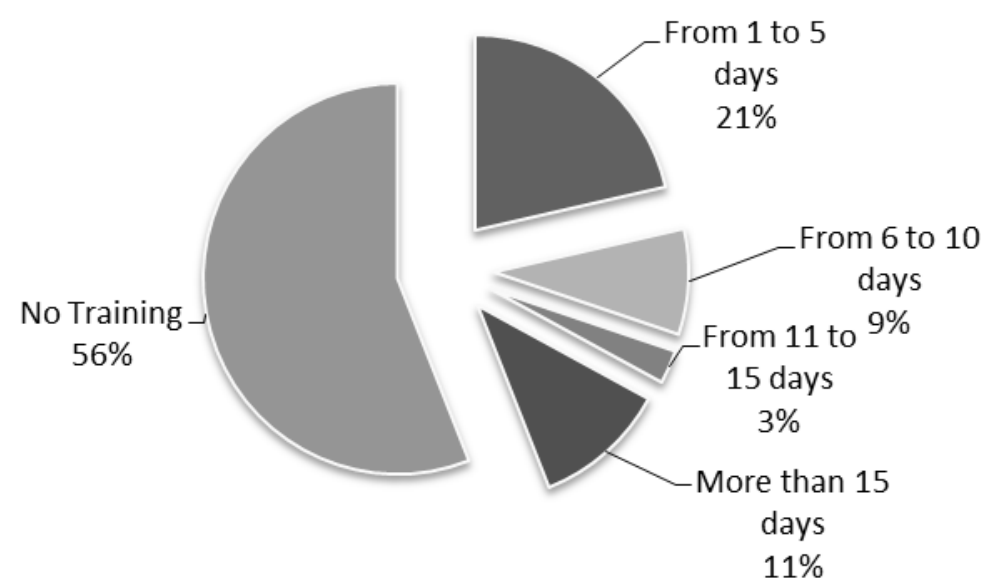

Furthermore, data highlight how they are not always mentored concretely to the specific company tutor (only in $35 \%$ of cases), specifically named in the training program, but rather directly to the head of the office $(37 \%)$ or the person who manages the relationships between companies and universities or the HR Manager (28\%).

Considering the operating conditions of interns (Figure 2), data shows how the trainee performs the tasks assigned with great autonomy and discretion, with high responsibility with respect to a specific project assigned, showing high availability to extend working time, as well as a total membership with the corporate culture. Less space seems to be left at the creative dimension or a proactive management, albeit within a high qualification of the assigned tasks. However, for such a commitment does not always corresponds adequate recognition in terms of integration of the trainee within the company: $51.9 \%$ have never been involved in an internal course reserved to all other employees, and $43.1 \%$ has not been granted access to some facilities or structures of the company, while almost a third have never had the chance to use software or tools reserved for normal employee or also a $30 \%$ was excluded from meetings and conferences. 
Figure 2. During an Internship, an Intern has to... (multiple choice-\%)

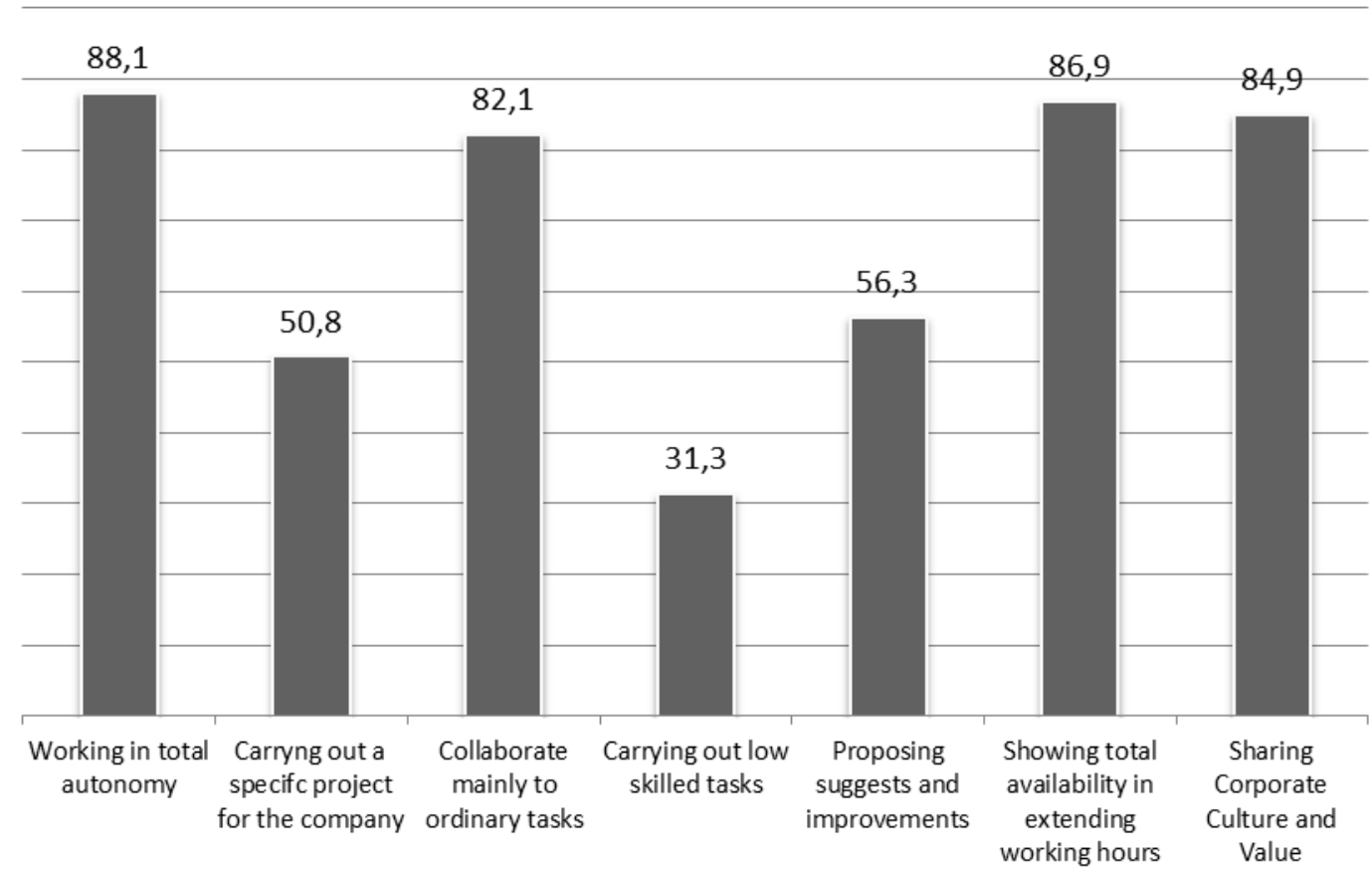

Moreover, $70 \%$ of trainees said they did not receive any refund that has been compulsory by law only after 2012 in Italy. The repayment to the trainee seem to be linked to the type of company and to the promoter of the internship program: $81 \%$ of trainees that worked in local firms did not receive any reimbursement, compared to $56 \%$ of interns that worked for national or multinationals companies. Similarly, internships activated at the university placement office show a slightly higher percentage in repayment compared to those activated by other proponents $(34.8 \%$ versus $27.3 \%)$. However, if we look at those few paid internships, the amount of reimbursement is higher in those placements activated outside of the university placement office $(77.7 \%$ of them have a reimbursement of up to 300 euro, while for internships activated by the University Placement Office the refund overcome 300 euro only in $36.4 \%$ of cases).

However, in a learning environment not always easy, interns in almost $70 \%$ of the cases declare to be satisfied with their training experience in terms of the skills learned, but more than $50 \%$ define it is not very useful from the point of view of finding a job.

\section{The Employability of Interns}

The trainees interviewed declared that $86 \%$ of them did not receive any proposal of employment at the end of this experience. The remaining $14 \%$ is made up of $11 \%$ who accepted this proposal and a $3 \%$ that rejected it because it was less skilled compared to their educational credentials or because it had been proposed to work without a contract. The $74 \%$ doesn't work currently, and only $6 \%$ work in the same company where they made the internship, which 
is associated with a further $7 \%$ claiming to work at least in the same industry. The remaining $13 \%$ is divided between those who preferred a path of selfemployment and those who have found work experimenting with entirely new paths. Having obtained a degree in 2011 or 2012 does not seem to have any effect on the current condition of employment (27.4\% of graduates in 2012 work compared with $25 \%$ of those in 2011).

In relation to the probability of being currently employed (Table 1), the values of the regression model calculated would show as between employability and internship there would be a negative relationship, albeit with a very low level of significance. The same thing goes for the internships activated with the support of University Placement Office. The employability of graduates would be more traditionally linked to the "strength" of their studies (b : 0.95 sig: 0.01): who has a degree in economics, engineering and medicine is employed more easily without making an internship, rather the provision of a period of extracurricular training may restrict or delay the entry opportunities on the labor market. However, certain conditions peculiar to the apprenticeship can play a positive role in employability of graduates, not so much the business features but rather the presence of a refund for the training activities carried out. Multivariate analysis, in fact, shows that the presence of a refund for the internship increase the probability of being employed (b:1.32 sig:0.00), demonstrating that this aspect represents not only a symbolic issue but a discriminating factor about the real quality of the experience that demonstrates the concrete commitment of the company in human resource training and its potential interest for recruiting interns.

An additional regression model was also calculated in relation to the perceived congruence between the work done and university studies (Table 2). The results of this new model, on one hand, further confirm the value of the dependent variables identified in the previous one: having a strong degree is much more significant in explaining also the congruence of the current work, but it is also the experience of a paid internship confirm that this item would also increase the selectivity in research of a future job. In addition, having done an internship through the support of the university placement office seems to have a positive influence on the congruence variable (b: $1.07 \mathrm{sig}$ : 0.03 ). Who went from university offices, in fact, is not currently working more than others or have better employment conditions, but he get most frequently a more congruent job with his studies. 
Table 1. Binary Logistic Regression- Probability to be Actually Employed

\begin{tabular}{|c|c|c|c|c|}
\hline & & B & Sig. & $\operatorname{Exp}(B)$ \\
\hline \multirow{4}{*}{ 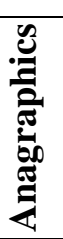 } & Female (rif.) & - & - & - \\
\hline & Male & $-0,053$ & 0,887 & 0,949 \\
\hline & Age: $<25$ years old (rif.) & - & - & - \\
\hline & Age: $\geq 25$ years old & 0,035 & 0,946 & 1,035 \\
\hline \multirow{6}{*}{ 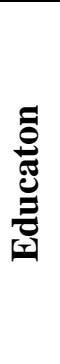 } & Not continue to study (ref.) & - & - & - \\
\hline & Continue to Study & 0,015 & 0,967 & 1,015 \\
\hline & Bachelor Degree (ref.) & - & - & - \\
\hline & Master Degree & $-0,411$ & 0,256 & 0,663 \\
\hline & Weak Degree (ref.) & - & - & - \\
\hline & Strong Degree & 0,957 & 0,010 & 2,605 \\
\hline \multirow{14}{*}{ 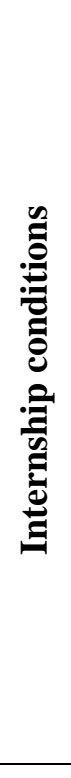 } & Never Made an Internship (ref.) & - & - & - \\
\hline & Made an Internship & $-1,315$ & 0,062 & 0,268 \\
\hline & Never gone to Univ. Placement Office (ref.) & - & - & - \\
\hline & University Placement Office User & $-0,935$ & 0,025 & 0,393 \\
\hline & No training during the internship (ref.) & - & - & - \\
\hline & Training during internship & 0,520 & 0,111 & 1,682 \\
\hline & No tutorship (ref.) & - & - & - \\
\hline & Tutorship & 0,257 & 0,481 & 1,293 \\
\hline & Duration: less than 6 months (ref.) & - & - & - \\
\hline & Duration: More than 6 months & $-0,644$ & 0,095 & 0,525 \\
\hline & No refund (ref.) & - & - & - \\
\hline & Refund & 1,325 & 0,000 & 3,764 \\
\hline & Local Firm (ref.) & - & - & - \\
\hline & Multinational or National Company & 0,350 & 0,362 & 1,419 \\
\hline & Nagelkerke R Square & & 0,395 & \\
\hline
\end{tabular}


Table 2. Binary Logistic Regression-Probability to get a Congruent with the University Degree

\begin{tabular}{|c|c|c|c|c|}
\hline & & B & Sig. & $\operatorname{Exp}(B)$ \\
\hline \multirow{4}{*}{ 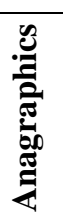 } & Female (rif.) & - & - & - \\
\hline & Male & 0,033 & 0,937 & 1,034 \\
\hline & \multicolumn{2}{|l|}{ Age: < 25 years old (rif) } & - & - \\
\hline & Age: $\geq 25$ years old & 0,352 & 0,591 & 1,422 \\
\hline \multirow{6}{*}{ 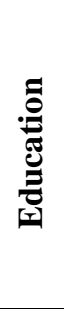 } & \multicolumn{2}{|l|}{ Not continue to study (ref } & - & - \\
\hline & Continue to study & 0,036 & 0,931 & 1,037 \\
\hline & Bachelor Degree(ref.) & - & - & - \\
\hline & Master Degree & $-0,204$ & 0,633 & 0,816 \\
\hline & Weak Degree (ref.) & - & - & - \\
\hline & Strong Degree & 1,581 & 0,000 & 4,860 \\
\hline \multirow{14}{*}{ 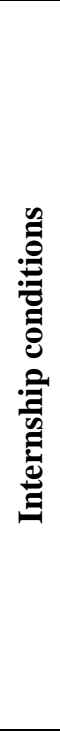 } & \multicolumn{2}{|c|}{ Never Made an Internship (ref.) } & - & - \\
\hline & Made an Internship & 2,765 & 0,002 & 0,063 \\
\hline & \multicolumn{2}{|c|}{ Never gone to Univ. Placement Office (ref.) } & - & - \\
\hline & University Placement Office User & 1,077 & 0,037 & 0,341 \\
\hline & \multicolumn{2}{|c|}{ No training during the internship (ref.) } & - & - \\
\hline & Training during internship & 0,465 & 0,236 & 1,593 \\
\hline & No tutorship (ref.) & & - & - \\
\hline & Tutorship & $-0,268$ & 0,558 & 0,765 \\
\hline & \multicolumn{2}{|c|}{ Duration: less than 6 months (ref.) } & - & - \\
\hline & Duration: More than 6 months & $-0,278$ & 0,542 & 0,757 \\
\hline & No refund (ref.) & & - & - \\
\hline & Refund & 1,518 & 0,000 & 4,561 \\
\hline & Local Firm (ref.) & - & - & - \\
\hline & Multinational or National Company & 0,514 & 0,243 & 1,673 \\
\hline \multicolumn{2}{|c|}{ Nagelkerke R Square } & & 0,597 & \\
\hline
\end{tabular}

\section{Conclusive Rermarks}

Data seem to confirm a serious shortage of the educational value of internship that, instead, would be the first objective of this tool, distinguishing it from ordinary forms of employment. The tutor plays mainly the role of a "bureaucrat", rather than embodies the role of guarantor and coach/mentor of the training process of the intern. This figure often does not provide any real support to interns or do not even have competence to do so. We only countersign the acts presented by the trainees, not participating in any way to monitor the content of the training project, abdicating the role of coach or mentor that the legislation would seem to give him. This element seems confirmed by the data on monitoring carried out on the interns: only about half of the respondents refer in daily or occasional conversations with a tutor or supervisor. This condition can bind a lack of skills possessed by the tutor 
appointed, which may not correspond to the characteristics of the role to play, or it can bind insider/outsider dynamic (Lindbeck and Snower 1988). A tutor, as insider, may perceive trainees as entrants and he fears that their presence could threat his position in the company. Therefore, it would be convenient to relegate the trainee in marginal functions limiting his coaching to a minimum, hindering the learning processes that should be supported. The figure is alarming in light of the shortcomings of the Italian system of monitoring and certification of skills acquired during the internship. Unlike the German model, the end of the internship is not subject to any real test of the skills learned. The legislation requires that the skills acquired during the training period are included in the so-called training booklet, a personal document prepared in electronic and printed form on which all the skills acquired, also during an internship, could be recorded. This so called "Europass model", defined by the Lisbon Strategy, after a trial period in 2010 in Italy, still suffers from a legal vacuum on the release mode, and the validation and identification of subjects that have to release it in the country. Moreover, data seem to confirm how trainees in the company live in a condition of role ambiguity, in which there is insufficient clarity about the information and the conditions in which they operate and expectations of bosses and colleagues respect to their tasks (Kahn et al. 1964). On one hand, it is expected that the intern will behave already as an internal resource but at the same time the conditions in which he operates seem to underline his status of extraneous. In particular, the analyzed data show that companies expect from trainees a full commitment to the values and the corporate culture, a total willingness to extend working times or extend the content of their job, as well as the ability to work independently, similar in all what they would expect from a regular employee according to a mutual exchange of obligations and rights which are defined in the "phsycological contract" (Rousseau and Snehal 1998). In practice, however, interns does not receive adequate training input, they remain confined to limited aspects of their job, failed to cross-cutting issues and overall knowledge on operating business, that somehow restrict their operational capability and understanding of production processes inside the company. A weak job coaching and supervision, combined with the exclusion from meetings or events or corporate training, or lack of access to facilities, tools and services reserved for the internal staff can help to strengthen their uncomfortable condition.

If we look at the employability dimension, certainly, the limited opportunities of employment are dependent on a predominant presence of internship experiences within small firms (with fewer than 15 employees), which operate mostly for the local market, and where almost a third are public bodies or no-profit organizations. For both the low returns in terms of employability of trainees in the same company are very vulnerable to the constraints of the context: a local economy, heavily oriented to microentrepreneurship with small projections on national or international markets, where most of the internship opportunities are guaranteed in public offices which has no chance to pursue the recruitment of trainee. The ability of internship to be a gateway into the world of work, often highlighted by many 
studies, can depend by the dynamics of a local labor market that often can mortify abilities and expectations of the younger educated workforce, as in the case of Southern Italy. An extracurricular training after graduation seem to restrict or delay the entry opportunities on the labor market, even if, the experience of the internship, through the mediation office placement, would lead to a lower risk of over-education and it would protect more the public and private investments in human capital.

In conclusion, training and monitoring of internships activities, less faced by the recent Italian reform, still remain the main critical aspects of this experience. First of all it's necessary empowering the involvement of the internship promoter, like labor agencies or University Placement Office, as guarantor of the quality of its learning worth. In fact, the conditions of the internship and its training value should be guaranteed both through increased attention to the choice of the company tutor to whom is entrusted the intern, also providing guidelines on tutorship, as in the case of Ireland, but also through a greater power of inspection and monitoring by the promoter, which in cases of misuse may decide to suspend or not to renew the agreement with the company. On this aspect, the legislator should intervene, as we can see in the recent Council Recommendation on a Quality Framework for Traineeship also, defining in detail a quality standard for internship and a system of the evaluation of this experience (through, for example, an exit interview or drafting a letter of reference, typical of the Anglo-Saxon model, or through the preparation of a certificate of competence, as in the French case, or a final exam that tests how much you really learned, as in the German case).

\section{References}

Adapt (2013) La regolazione dei tirocini formativi in Italia dopo la legge Fornero [The regulation of internships in Italy after the Fornero law], Adapt e-book vol. 16, Bergamo, BG: Adapt University Press.

Avola M, Cortese A (2013) Istruzione e qualità dell'occupazione in Sicilia [Education and quality of employment in Sicily]. Sprechi di capitale umano fra vincoli strutturali e irresponsabilità pubbliche. Scuola Democratica 2(2): 379-400.

Collins R (1972), The credential society. New York, NY: Academic Press.

Granovetter M (1973) The Strength of Weak Ties. American Journal of Sociology 78(2): 1360-1380.

Hanson AR, Carnevale A, Gulish A (2013), Failure to launch. Structural Shifts and the new Lost Generation, Full Report Georgetown University, Washington, WA.

Kahn RL, Wolfe DM, Quinn PR, Rosenthal R, Snoek DJA (1964) Organizational Stress. Studies on Role Conflict and Ambiguity. New York: Wiley and Son.

Lindbeck A, Snower D (1988) The Insider-Outsider Theory of Employment and Unemployment. Cambridge: MIT Press.

McKinsey (2012) Education to Employment: Getting Europe's Youth into Work. Bruxelles, BRU: McK Report.

Mouw T (2003) Social capital and finding a job: Do contacts matter?. American Sociological Review 68(6): 868-898. 
Muller W, Gangl M (2003) Transitions from education to work in Europe. The integration of Youth in EU Labour Markets. New York, NY: Oxford University Press.

Peschner J (2013) Traineeships in Europe - their quality, their impact on labour market, outcomes, Eurobarometer 378, Bruxelles, BRU.

Regini M (2010) European Universities and the Challenge of the Market: A Comparative Analysis. London: Edward Elgar.

Reyneri E, Pintaldi F (2013) Dieci domande sul mercato del lavoro in crisi Ten questions on the labor market in crisis]. Bologna, BO: Il Mulino.

Rousseau D, Snehal AD (1998) Assessing psychological contracts: issues, alternatives and measures. Journal of Organizational Behavior 19(1): 679-695.

Spence M (1973) Job Market Signaling. The Quarterly Journal of Economics 87(3): 355-374.

Standing G (2011) The Precariat. The new dangerous class. London: Bloomsbury Publishing.

Walther A (2006) Regimes of youth transitions. Choice, flexibility and security in young people's experience across different European countexts, Young: Nordic Journal of Youth Research 14(2): 119-139. 
